\title{
A YEAR OF PAEDIATRIC CARDIOVASCULAR ANAESTHESIA
}

\author{
Davm Allan, M.B , CH B , A. W. Conn, M D., B SC.( MEd.), F.R.C P.(C), \\ and C. I. JunkIN, M.B. ${ }^{\text {T }}$
}

Paediatric CaRdiovascular ANAesthesia necessitates the application of the basic principles of anaesthesiology at a very high critical level. Maximal oxygenation of the patient is paramount The anaesthetic agent employed should je nonexplosive, easy to reverse, and have minimal side-effects, especially on the cardiovascular system. Many methods of anaesthesia, utilizing various combinations and permutations of pharmacological agents, are being used successfully. The methods vary, the principles are the same. This is an account of one such method, employed the past year at the Hospital for Sick Chldren, Toronto

\section{METHOD}

Assessment of the patient. The patient is carefully examined preoperatively with special reference to the tyse of anomaly and the degree of cardiac fallure. Certain anomalies, best exempli ied by total anomalous pulmonary venous drainage, attenuate the conduct of anaesthesia considerably.

Premedication. Atropine gr. 1/5,000/lb approximately and meperidine 0.75 $\mathrm{mg}$./lb. is given $1 / 2$ hour preoperatively. Exceptions to this rule are the older apprehensive children who are given morphine, and poor risk infants to whom atropine alone is ziven under direct supervision L.ght sedation is successfully employed at this aspital as the children awaiting surgery are "mothered" and generally entertained.

Induction. Thiopentone $2 / 1 / 2$ per cent is injected very slowly in a minimal "sleeping" dose. An endeavour is made throughout to use all pharmacological agents by a titration technique. The aim is to give the least amount possible to gain the desired effect. A time/patient/defect relationship is considered at all times.

Intubation is carried out with the aid of succinylcholine after spraying the cords with $\mathbf{5}$ per cent hexylcaine. Infants are induced with Fluothane, or oxygen alone is used, before intramuscular succinylcholine is given for intubation. Hexylcaine is not employed in this instance

Adequate oxygenation with close supervision of the patient is the essence of the technique.

Maintenance. Fluothane in the percentage range of 0.5 to 1.0 is generally adequate. Oxygen is the vaporizing agent.

Respirations are controlled when surgery of the chest is begun. Infants are controlled throughout. Hyperventilation is employed.

Succinylcholine chloride in the dilution of $1 \mathrm{mg} . / 10 \mathrm{lb} . / \mathrm{ml}$. is connected to the intravenous. To avoid over-hydration in infants under $20 \mathrm{lb}$, the dilution is not

1From the Department of Anaesthesia, Hospital for Sick Chuldren, and University of Toronto, Toronto. 
taken below $2 \mathrm{mg}$. $/ 1 \mathrm{ml}$. The succinylcholme is used to posture the patient under hypothermia, to test compliance, and to control the patient during extracorporeal circulation occlusions. It has been found that the amount of succinylcholine used is in inverse proportion to the experience of the anaesthetist in this technique.

Infants as a rule are difficult to keep anaesthetized with Fluothane under a 20 per cent concentration. A combination of 1.0 per cent Fluothane with intermittent intramuscular or intravenous succinylcholine is a good alternate.

Preservation of function. Preservation of physiological function in cardiovascular patients is frequently more difficult than usual. The control of anaesthesia in relation to function necessitates, in many instances, the vise of instrumentation as an adjunct to the "five senses."

Various combinations and permutations of the following monitors have been used: oesophageal stethoscope; endotracheal pressure manometer; oesophageal thermometer; oscillometer; arterial manometer, superior and inferior vena caval manometers; electrocardiograph; electroencephalograph; direct intracardiac manometer; oxygen saturation recorder, rectal thermometer, and qualitative and quantitative area dye dilution apparatus.

Temperature is controlled by a twin tank (hot/cold) blanket arrangement.

Blood volume must be maintained and it is essential to ensure adequate facilities for rapid blood replacement based on a clinical appraisal of the patient, utilizing the instrumentation, measurement of suction, weighing of sponges, and weighing of the patient.

Blood chemistry is monitored by a $\mathrm{pH}$ meter and laboratory facilities are readly available. Instrumentation is also used in the recovery phase.

Post-anaesthetic care. The patients are taken to the recovery room awake and in physiological balance. The same diligent supervision of the patient is employed here as in the operating room. Meperidine, in a dose $1 \mathrm{mg} . / 10 \mathrm{lb}$. intravenously, is used for pain relief.

Maintenance of maximal oxygenation necessitates control of "splinting" due to pain, adequate drainage of mediastinal and chest cavities, clearing of the airway by oronasal or bronchoscopic suction, and the treatment of cardiac failure. The intermittent use of positive pressure, either manually or mechanically, may be necessary to ensure adequate ventillation. The use of dry gases is discontinued as soon as possible. Blood volume and acid/base balance are controlled as before.

The commonest pharmacological agents used are: Aminophyllin and Cortisone for bronchospasm; Prostigmine for supraventrieular tachycardia; Isuprel, Acetylstrophanthidine, and Digoxin for cardac failure; and calcium gluconate to obviate citrate intoxication.

Constant care of the patient continues as long as necessary. This time varies from hours to days.

Factor of basic pathology. To illustrate the defect/age/weight relationship of our series, Table I is presented. No attempt is made to classify t te defects in detail or to illustrate the important factor of secondary change, such as pulmonary hysertension; but it should be remembered that many of the anomalies present incividual anaesthetic problems. It is only with a full understanding of the anomaly that the problems can be appreciated. The significant factor of the 
TABLE I

\begin{tabular}{|c|c|c|c|}
\hline Defect & No & Age range & $\begin{array}{l}\text { Werght range } \\
\text { (lb /oz ) }\end{array}$ \\
\hline \multicolumn{4}{|l|}{ Hypothermia } \\
\hline Coarctation of the aorta & 19 & 4 wks -12 yrs & $7 / 3-106$ \\
\hline Tetralogy of Fallot & 15 & $4 \frac{1}{2} \mathrm{mo}-15 \mathrm{yrs}$ & $9-75$ \\
\hline Tricuspid atresia & 8 & $3 \mathrm{mo}-2$ yrs & $7 / 10-20$ \\
\hline Single ventricle & 3 & $3-11$ yrs & $30-55$ \\
\hline$T A P V D$ & 1 & 8 wks. & $9 / 3$ \\
\hline $\begin{array}{l}\text { Pulmonary atresia and } \\
\text { PD A }\end{array}$ & 1 & & \\
\hline A S D secundum & 30 & $4-14$ yrs & $35-91$ \\
\hline Pulmonary st & 14 & $1 \mathrm{wk}-15$ yrs & $5 / 6-112$ \\
\hline A S D primur & 1 & $14 \mathrm{yrs}$ & 105 \\
\hline \multicolumn{4}{|l|}{ Extracorporeal circulation } \\
\hline V S D & 34 & $3 \mathrm{mo}-14 \mathrm{yrs}$ & $9-99$ \\
\hline Aortic stenosis & 3 & $2-12$ yrs & $26-98$ \\
\hline Aortic and mitral stenosis & 1 & $15 \mathrm{mo}$ & 13 \\
\hline Tetralogy of Fallot & 8 & $3-5$ yrs & $26-37$ \\
\hline A S D secundum & 2 & $11-15$ yrs & $59-80$ \\
\hline Miscellanec & 2 & $6-10$ yrs & $34-55$ \\
\hline Transposition of G V & 4 & $2 \mathrm{wks}-23 \mathrm{mo}$ & $6-15 / 9$ \\
\hline A S D and mitral cleft & 7 & $2-5$ yrs & $26-36$ \\
\hline TAPVD & 7 & $2 \mathrm{mo}-11 \mathrm{yrs}$ & $10 / 3-80$ \\
\hline P.A P V D & 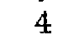 & $9-15$ yrs & $61-91$ \\
\hline \multicolumn{4}{|l|}{ Others } \\
\hline Vascular rings & 2 & $2 \mathrm{mo}-14 \mathrm{mo}$ & $14 / 13-22$ \\
\hline P D & 38 & $3 \mathrm{wk}$ & $7 / 10-155$ \\
\hline
\end{tabular}

anomaly may modify responses to drugs. For example, in the patient with tetralogy of Fallot, the slow circulation time delays the onset of sleep following the injection of thiopentone The pathology may be multuple, involving varying pharmacological and mechanical controls of respiration This is very well demonstrated in a patient with a vascular ring pathology. These rings compress the trachea either preoperatively and/or postoperatively.

In addition, not only do these children frequently rresent as repeated pneumonitides, but there is often concomitant congen.tal malformation of the tracheobronchial tree. It should suffice to mention that one of these children, after having been vigorously treated with antispasmodics for bronchospasm during the operation, presented a very difficult mechanical factor postoperatively This involved eleven bronchoscopic suctions in as many days.

The manner in which an anaesthetic technique can materially benefit the welfare of a group of patients is well seen in the correction of the anomaly of coarctation of the aorta. Previous to the introduction of Fluothane, the mainstay of anaesthesia was nitrous oxide/oxygen with intermittent decamethonium and succinylcholine. When the aorta was occluded, Arfonad was frequently necessary to control the resulting hypertension. Again, on removal of the clamps, a vasoJressor had to be employed to control the sudden hypotension. To replace this -nigh-dose relaxant technique with its inherent dangers, Fluothane was chosen. Not only did it afford a method of using 100 per cent oxygen to ventilate, but also in our opinion, it satisfied the criteria for a cardiovascular anaesthetic. This we selieve has been borne out in practice. Fluothane in the range of $0.5-1.0$ per cent does not act as an irritant to the pulmonary and cardiovascular systems. 
Cardiac output determinations were done but not in sufficient quantity to be statistically significant, but it appears that in the range $0.5-1.0$ per cent. Fluothane does not materially affect the cardiac output. The most remarkable finding during the use of Fluothane has been the excellent stability of the patient's cardiovascular system. At no time since the advent of Fluothane have Arfonad and vasopressors been used during the correction of coarctation of the aorta.

Factor of Occlusion. Following either an extracorporeal or a hypothermic occlusion, nitrous oxide 60 per cent with oxygen given by hyperventılation is usually adequate, at least for a considerable time. It is also preferable to use this technique at the end of the operation as Fluothane has a longer "wake-up" time.

Factor of age. Infants present a multitude of problems, only a few of which will be mentioned here. Many of the poorer risk infants do not tolerate any degree of anaesthesia. It is our custom to ventilate with 100 per cent oxygen and use intermittent succinylcholne after adequate atropine to keep the child still. Great care is taken that the retracted lung is frequently inflated and that major vessels are not accidently occluded. Every facet of the method is modified by the infant It is found, for example, that the best guide for blood replacement in the operating room is direct vision of the atria, while in the recovery room, the venous pressure of the "cut-down" is a valuable index. Many infants warrant surgery on an emergency basis. There is no time to check acid/base balance and to attempt to bring it within physiological limits. Thus, postoperatively, diligent watch must be made for acidosis. This may arise on the second or third day after the operation. These infants must be vigorously treated and it is often necessary to ventilate them manually to ensure adequate oxygenation. In infant care, normal trials and tribulations are magnified a thousand times, but there is something peculiarly satisfying in the reward of success. These infants have a normal life expectancy.

Factor of constant care. The recovery phase is, in our opinion, no less important than the operative one. The same constant care is not only desirable, it is an absolute necessity. Three illustrations should suffice to demonstrate the degree of vigilance necessary.

Eight hours sosto seratively a main ventriculotomy suture breaks. There is a massive tamponade and carciac arrest. There is an anaesthetist and surgeon preserit. The heart is restarted and repaired instantly. The child has no sequelae.

One hour postoperatively a $40 \mathrm{lb}$. child has a cardiac arrest. Surgeons and anaesthetists are present. The heart is restarted, but it is found that it is impossible to adequately inflate the lungs manually. A Bennet Assistor is then used at its maximum sjeed and ventilatory power. Gradually the lungs (which have a consistency of liver) in.late, and adequate oxygenation is achieved. The child is well.

Four hours postoperatively, a $30 \mathrm{lb}$. child does not a opear to be trogressing satisfactorlly. Although pulse and blood pressure are normal, t ie pallor of tre child indicates blood loss unaccounted for and/or inadequate ventulation. The right main brorchus occludes and bronchoscopic suction is immediately carried out with minimal suscess although the right lung has now good arr entry. But on returning the patient to the recovery room, there is again dimınished air entry on the right side. Again bronchoscopy is carried out and the bronchøscopist states that the right: stem bronchus is now compressed, which it had not been on the first examination. A thoracotomy is performed and a large amount of clots removed. The child rapidly begins to improve. 
These brief illustrations of success following constant care should serve to make one aware that the anaesthetist must not relax his vigilance and degree of service immediately postoperatively.

\section{SUMMARX}

A method of anaesthesia for paediatric cardiovascular surgery has been presented. It has been used successfully for the past year at the Hospital for. Sick Children, Toronto. 